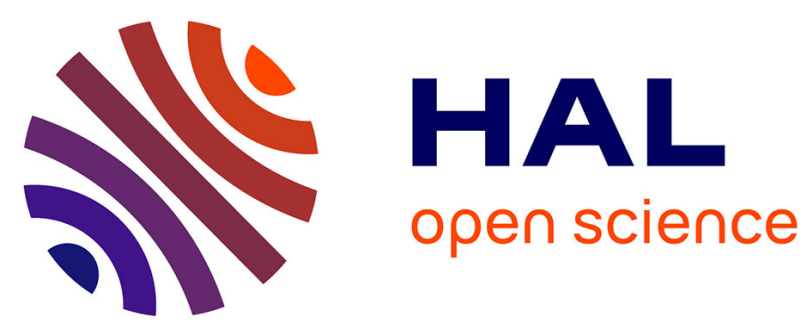

\title{
Static Sorption of Phenol and 4-Nitrophenol onto Composite Geomaterials based on Montmorillonite, Activated Carbon and Cement
}

Mohamed Houari, Boualem Hamdi, Omar Bouras, Jean-Claude Bollinger, Michel Baudu

\section{To cite this version:}

Mohamed Houari, Boualem Hamdi, Omar Bouras, Jean-Claude Bollinger, Michel Baudu. Static Sorption of Phenol and 4-Nitrophenol onto Composite Geomaterials based on Montmorillonite, Activated Carbon and Cement. Chemical Engineering Journal, 2014, 255, pp.506-512. 10.1016/j.cej.2014.06.065 . hal-01024406

\section{HAL Id: hal-01024406 \\ https://hal-unilim.archives-ouvertes.fr/hal-01024406}

Submitted on 16 Jul 2014

HAL is a multi-disciplinary open access archive for the deposit and dissemination of scientific research documents, whether they are published or not. The documents may come from teaching and research institutions in France or abroad, or from public or private research centers.
L'archive ouverte pluridisciplinaire HAL, est destinée au dépôt et à la diffusion de documents scientifiques de niveau recherche, publiés ou non, émanant des établissements d'enseignement et de recherche français ou étrangers, des laboratoires publics ou privés. 


\section{Static Sorption of Phenol and 4-Nitrophenol onto Composite}

\section{Geomaterials based on Montmorillonite, Activated Carbon and}

\section{Cement}

Mohamed Houari a, b, Boualem Hamdi ${ }^{\text {c }}$, Omar Bouras ${ }^{\text {b }}$, Jean-Claude Bollinger $^{a *}$, Michel Baudu ${ }^{\text {a }}$

${ }^{a}$ Université de Limoges, Groupement de Recherche Eau Sol Environnement (GRESE), Faculté des Sciences \& Techniques, 123 avenue Albert Thomas, 87060 Limoges (France)

${ }^{\mathrm{b}}$ University of Blida, Department of Chemical Engineering, P.O. Box 270, 09000 Blida (Algeria)

' Laboratoire d'Etude Physico-Chimique des Matériaux et Application à l'Environnement (LEPCMAE), Faculté de Chimie, Université des Sciences \& de la Technologie Houari Boumediene (USTHB), BP 32 El Alia, 16111 Alger (Algeria)

* Corresponding author. Tel.: +33 624307 201; fax: +33 555457203 .

E-mail address: jean-claude.bollinger@unilim.fr (J.C. Bollinger).

\section{Paper published in}

Chemical Engineering Journal 255, 506-512 (2014)

(DOI 10.1016/j.cej.2014.06.065) 


\begin{abstract}
This paper studies the sorption of phenol and 4-nitrophenol (4NP) onto solid sorbents derived from mixtures of montmorillonite, activated carbon (AC) and cement, denoted herein MACC. These materials are mesoporous and some of their physicochemical properties have been measured and discussed. The weight fraction $X_{1}(\%)$ of montmorillonite in the mixtures strongly influences the sorbate removal rate. The sorption isotherms were experimentally established by batch testing on geomaterials with various $X_{1}$ values at $20^{\circ} \mathrm{C}$ and at different $\mathrm{pH}$ values (from 3 to 8 ). The Langmuir model correctly fits the sorption isotherm data $\left(\mathrm{R}^{2}>0.95\right)$. The results show increased sorption behavior for both phenol and $4 \mathrm{NP}$ on the composite geomaterials compared to the pure components, yielding the order: MACC $>\mathrm{AC}>$ montmorillonite.
\end{abstract}

\title{
Keywords
}

Composite geomaterials; Phenols; Sorption isotherms; Montmorillonite; Activated carbon. 


\section{Introduction}

In industry as well as day-to-day life, substituted phenolic compounds are widely used. Due to their high stability, high toxicity and carcinogenic nature however, they have caused considerable damage and threaten ecosystems both in water bodies and for human health. The efficient elimination of phenolic compounds in wastewater has thus become an urgent need. Conventional wastewater treatment techniques include photocatalytic degradation processes, chemical oxidation and biological digestion, in which sorption onto activated carbon constitutes one of the most widely studied technologies. Recent research has focused on the types and modification of clay-based sorbents, the corresponding sorption principles or mechanisms, and the factors influencing both sorption rate and kinetics $[1,2]$.

Phenol, a small but important organic molecule, appears as an end or side group in a number of polymers. Furthermore, phenol is a frequent and toxic byproduct of industrial processes and thus causes concern from an environmental perspective. The use of activated carbon to remove phenol from aqueous solutions, for industrial and environmental applications, has been primarily motivated by a physisorption mechanism due to dispersive forces $[3,4]$.

Phenol was chosen as the study target herein, given its status as an intermediate product in the oxidation pathway of higher molecular weight aromatic compounds. Mononitrophenols can be classified as compounds exhibiting moderate to high toxicity in the aquatic compartment [5]. Based on information gathered, 4-nitrophenol (4NP) will enter the environment during its production and then be used as an intermediate product in the manufacturing of parathion, methyl-parathion and $\mathrm{N}$-acetyl- $p$-aminophenol [6]. For this reason, it has been selected as a comparative model molecule in the present study. 
Swelling 2:1 clay minerals play an important role in a number of engineering and environmental processes. These clays consist of negatively charged silicate layers; their negative charges are compensated by interlayer counterions, which along with the charged clay mineral surfaces strongly interact with polar solvents, most notably water. This interaction results in the well-known swelling of smectites and vermiculites. Clay swelling can lead to the sorption of organic molecules and an exchange of cations, two processes that are of environmental concern. The swelling properties of clay minerals are utilized in applications for their role as an adsorbent, ion exchanger and molecular sieve catalyst $[2,7]$.

In recent years, reusable organo-inorgano-clay sorbents have been increasingly introduced for their capacity to efficiently remove phenols and many micropollutants from wastewater, as well as for their good sorbent properties and mechanical stability [8-25]. This heightened interest stems from the adsorption properties and high specific surface area of clay, the high volume of micropores and the broad range of surface functional groups introduced into clay structures.

With dependable availability in nature, clay is able to remain inexpensive. The purpose of the present investigation is to synthesize geomaterials (MACC) based on two sorbent materials with very distinct properties (namely, Na-montmorillonite and activated carbon) and a binder, i.e. cement [26 - 28]. These constituents were chosen in order to associate a convenient mechanical stability (contributed by the cement and partially by the clay) with the complementary sorptive properties of both the hydrophilic clay and the lipophilic activated carbon.

This combination of adsorptive capacities for clay and activated carbon has been examined by assessing the extent of sorption and by removing two model phenolic 
compounds: phenol and 4NP were chosen herein given their status as two of the most challenging priority pollutants to be eliminated from waste streams and groundwater.

The porous nature of these geomaterials and their high internal surface area constitute favorable properties for sorption. A more extensive investigation of the effect of the montmorillonite weight fraction on sorption kinetics has also been undertaken. An attempt has been made herein to apply a simple sorption model to predict both the sorption isotherms and kinetics.

\section{Materials and methods}

All reagents were of analytical grade and used without further purification. The various solutions were prepared in high purity de-ionized water (HPW) (Milli-Q system: resistivity of $18.2 \mathrm{M} \Omega \mathrm{cm}, \mathrm{TOC}<10 \mu \mathrm{g} / \mathrm{L})$. All glassware and containers were previously soaked in $10 \%(\mathrm{v} / \mathrm{v})$ nitric acid for at least $24 \mathrm{~h}$ and then rinsed with HPW.

\subsection{Sorbates}

Phenol ( $\geq 99 \%)$ and 4NP ( $\geq 99 \%)$, purchased from Sigma-Aldrich, were chosen as the sorbates; they were used without further purification. A number of useful physicochemical properties are listed in Table 1.

\subsection{Sorbents: starting materials}

Bentonite from the Maghnia deposit (western Algeria), obtained from the ENOF Company (Algeria), was used as a starting material; it is composed essentially of montmorillonite (75\%) with minor impurities (quartz, feldspar, calcite, etc.). Its cation exchange capacity of $86.510^{-5} \mathrm{eq} / \mathrm{g}$ was determined according to the sodium acetate saturation method [31], applicable to materials containing appreciable amounts of clays. Moreover, its chemical composition and purification method were described previously [27] and will be briefly summarized herein. The raw bentonite was dispersed in $1 \mathrm{~mol} / \mathrm{L}$ 
$\mathrm{NaCl}$ solution in order to obtain homoionic Na-montmorillonite and then separated from the solution and washed several times with high-purity water (HPW). A 2 wt.\% suspension was placed in graduated cylinders to allow particles $>2 \mu \mathrm{m}$ to settle. The suspension at a depth of $10 \mathrm{~cm}$ was collected with an Andreasen pipette. This operation was repeated several times until the suspension became almost transparent at the $10-\mathrm{cm}$ depth. The particles collected smaller than $2 \mu \mathrm{m}$ were recovered by centrifugation, washed with HPW and finally dialyzed to eliminate the excess chloride ions. After drying $48 \mathrm{~h}$ at $40{ }^{\circ} \mathrm{C}$, the sample was pulverized to pass through a $200-\mu \mathrm{m}$ sieve. This fraction was used in the geomaterial preparation process.

The activated carbon used is a commercially available activated wood coal (Fluka) with a microporous structure; it was ground and sieved at $<20 \mu \mathrm{m}$ before use. The cement (produced at the Chlef plant, in western Algeria) is a fine powder containing $94.8 \% \mathrm{w} / \mathrm{w} \mathrm{SiO}_{2}$. The main properties of these raw solid sorbents are shown in Table 2.

\subsection{Preparation of geomaterials}

The composite geomaterials (MACC) were prepared by mixing the 3 constituents Na-montmorillonite $\left(X_{1} \% \mathrm{w} / \mathrm{w}\right)$, activated carbon $\left(X_{2}\right)$ and cement $\left(X_{3}\right)$ with water. Three different weight fractions of Na-montmorillonite $\left(X_{1}=60,70,80 \%\right)$ were mixed with a fixed amount $X_{2}=7 \%$ of activated carbon and complementary fractions of cement (i.e. $X_{3}=33 \%, 23 \%, 13 \%$, respectively) under mechanical mixing at medium speed (40 rpm) (W49121 powder mixer from Fisher Scientific) for $24 \mathrm{~h}$ at ambient temperature. After adding water $(1 \mathrm{~mL}$ per $1 \mathrm{~g}$ of solid mixture) and more mechanical mixing for $48 \mathrm{~h}$ at $40 \mathrm{rpm}$, the final solid was stored in a drying cupboard ( $48 \mathrm{~h}$ at 40 ${ }^{\circ} \mathrm{C}$ ), ground and sieved at $<250 \mu \mathrm{m}$. The pertinent characteristics of these MACC geomaterials are provided in Table 3. 


\subsection{Determination of physical and chemical properties of sorbents}

To access the various physicochemical properties of our sorbents (either raw solids or synthesized geomaterials), we applied classical methods; the experimental results are presented in Tables 2 and 3.

The zeta-potential for the various kinds of colloidal particles was obtained with a Zetaphoremeter III model Z3000 from CAD Instrumentation [32], by measuring their mobility in an electric field. Sample dispersions were prepared by mixing $1 \mathrm{~g}$ of airdried solid with $25 \mathrm{~mL}$ of $0.01 \mathrm{~mol} / \mathrm{L} \mathrm{KCl}$ aqueous solution followed by a 24-h equilibration. Each result was reported as an average of 3 readings at $22 \pm 2{ }^{\circ} \mathrm{C}$. The values of the $\mathrm{pH}$ of zero point charge $\left(\mathrm{pH}_{\mathrm{zpc}}\right)$ were derived from a titration method [33].

The specific surface area $\left(\mathrm{S}_{\mathrm{BET}}\right)$, pore size distribution and pore volume of all solid sorbents (previously outgassed at $200{ }^{\circ} \mathrm{C}$ for $8 \mathrm{~h}$ under 0.1 torr vacuum ) were determined by physical adsorption of nitrogen at $-196^{\circ} \mathrm{C}$ using a Micromeritics ASAP2000 analyzer.

\subsection{Sorption kinetics}

Kinetic studies were conducted in a series of seven identical 200-mL HDPE flasks. A fixed mass $(1.5 \mathrm{~g})$ of MACC sorbent was added to $100 \mathrm{~mL}$ of a $0.71810^{-3}$ $\mathrm{mol} / \mathrm{L}$ aqueous solution of the phenolic compound and then shaken in the dark at 400 rpm on an orbital shaking table (Ikalabortechnik K550) at room temperature $(22 \pm 2$ ${ }^{\circ} \mathrm{C}$ ). A $3 \mathrm{~mL}$ aliquot was sampled in a given separate flask at a chosen time (for a total time of 72 hours), filtered at $0.45 \mu \mathrm{m}$ and analyzed to determine the solution concentration. Each experiment was duplicated, with blanks constituted without sorbent and/or without sorbate.

\subsection{Sorption isotherms}


All sorption isotherms were obtained in a batch reactor. Due to their high aqueous solubility, the stock solutions of phenol and 4NP were prepared directly as an aqueous solution: the initial concentration chosen for both tested compounds was 0.718 $10^{-3} \mathrm{~mol} / \mathrm{L}$. A $100-\mathrm{mL}$ aliquot of these solutions was mixed (in a 200-mL HDPE bottle) with a given amount (from 0.01 to $1.5 \mathrm{~g}$ ) of the selected solid MACC geomaterial (with a given montmorillonite weight fraction $X_{1}$ ). The chosen mass of sorbent was set to achieve 60\%-90\% sorption efficiency. At least 2 replicates and a blank for the given concentration were agitated in the dark at $400 \mathrm{rpm}$ (Ikalabortechnik K550 orbital shaking table) for $2 \mathrm{~h}$ at room temperature $\left(22 \pm 2{ }^{\circ} \mathrm{C}\right)$. Preliminary kinetic experiments indicated that this length of time was sufficient to establish equilibrium. The $\mathrm{pH}$ of the aqueous solutions was controlled at values of 3, 5 and 8 by adding small amounts of concentrated $0.1 \mathrm{~mol} / \mathrm{L} \mathrm{HNO}_{3}$ or $\mathrm{NaOH}$ solutions.

At the end of the sorption step, $3 \mathrm{~mL}$ aliquots were removed and filtered (at 0.45 $\mu \mathrm{m})$ for the quantitative analysis. The final $\mathrm{pH}$ of the supernatant was measured after each sorption experiment: these $\mathrm{pH}$ values remained practically unchanged ( \pm 0.1 unit).

Phenol and 4NP equilibrium concentrations in the supernatants were obtained from absorbance measurements (M40 Shimadzu UV-spectrophotometer) at their characteristic maximum wavelength $\lambda_{\max }$, as given in Table 1 . The sorbed amount of solute was calculated by difference.

Isotherms consisted of seven to eight concentration points; moreover, each point, including the blank, was run in duplicate.

\subsection{Data analysis}

The equilibrium sorption isotherm data were fitted with the Langmuir model:

$$
q_{\mathrm{e}}=\left(K_{L} q_{\max } C_{\mathrm{e}}\right) /\left(1+K_{L} C_{\mathrm{e}}\right)
$$

where $q_{\mathrm{e}}$ : equilibrium concentration on the sorbent (in $\mathrm{mol} / \mathrm{g}$ ), 
$C_{\mathrm{e}}$ : equilibrium concentration in solution $(\mathrm{mol} / \mathrm{L})$,

$q_{\max }$ : maximum capacity of the sorbent $(\mathrm{mol} / \mathrm{g})$,

and $K_{L}$ refers to the Langmuir adsorption constant $(\mathrm{L} / \mathrm{mol})$, which is correlated with the sorption energy. This Langmuir equation is applicable to homogeneous sorption, in which the sorption of each sorbate molecule onto the surface contains equal sorption activation energy. The unknown constants of this model equation are found using a nonlinear least squares data treatment available in the Origin v.7 software package.

\section{Results and Discussion}

The MACC geomaterial constituents were chosen in order to associate the mechanical strength due to cement and partly to clay with the complementary sorption properties stemming from the presence of both activated carbon and clay minerals.

\subsection{Physicochemical properties of solid sorbents}

BET specific surface area and pore volume are presented in Table 2 for pure montmorillonite, activated carbon and cement, along with their cation-exchange capacity and $\mathrm{pH}_{\mathrm{zpc}}$ values, while Table 3 provides the same data for the MACC composite geomaterials. Let's point out the net decrease in CEC values of the MACC relative to pure montmorillonite. These values reflect the difference in charge distribution as well as the presence of cement coatings. The pore size distribution curves display a single broad peak, centered at around $1.2 \mathrm{~nm}$ (detailed data not shown). In the pore size range $<1.0 \mathrm{~nm}$, the cumulative pore volume of MACC is greater than that of pure montmorillonite. It can thus be concluded that the assembly method for the various components had generated a structure with smaller micropores. As seen in Table 3, when compared with the original materials (Table 2), MACC geomaterials are 
characterized by an increase in BET surface area and pore volume as the montmorillonite percentage $X_{1}$ increases.

Zeta-potential measurements of geomaterial suspensions are commonly used to characterize montmorillonite, cement and activated carbon particles: the experimental measurements of electrophoretic mobility of these particles may be converted into the zeta-potential value [32]. This step actually requires a certain theoretical idealization of the systems under study, in assuming that the solid particles are spherical and that the electric charge of the particles is uniformly distributed throughout the surface. It is clear that neither of these requirements are strictly applicable to clay particles in suspension. For example, let's note the coexistence of positively-charged edges and negativelycharged sides on the clay platelets $[34,35]$.

Nevertheless, it is still possible to obtain valuable information on the clay surface charge by measuring sufficiently consistent values of zeta-potential, at the specific $\mathrm{pH}$ value of the clay suspension that would ensure neutrality of the charge on edges (isoelectric point): i.e. at $\mathrm{pH} \sim 8.3$ and 10-11 for montmorillonite and MACC, respectively. The zeta-potential values for the pure components in $0.01 \mathrm{~mol} / \mathrm{L} \mathrm{KCl}$ solutions at $\mathrm{pH} 8$ exhibit a net negative value (Table 2 ). The data presented in Table 3 clearly demonstrate a significant increase in zeta-potential of the studied MACC samples due to the introduction of various weight fractions $X_{1}$ of montmorillonite. It is worthwhile to mention that the zeta-potential of the original montmorillonite sample is much greater than that of the MACC matrices: this is not a surprising result given the well-established formation of hydroxy/oxide films on clay mineral surfaces, masking their original surface charge [36]. As our study has revealed, adding cement $\left(X_{3} \%\right)$ and activated carbon $\left(X_{2}=7 \%\right)$ to montmorillonite sharply decreases the zeta-potential by nearly half. 


\subsection{Sorption kinetics}

In order to select the optimal contact time for isotherm experiments, we first conducted kinetic studies at $\mathrm{pH} 3$ with both the MACC sorbents and their pure constituents, using the same grain size $(250 \mu \mathrm{m})$. The sorption rate decreases over time until gradually approaching a plateau due to the continuous decrease in the concentration driving force (Fig. 1). The data can be represented by a pseudo-first order rate, and a direct relationship between the maximum sorption capacity and $X_{1}$ is clearly visible. Moreover, we observe an increase in the maximum capacity for $X_{1} \geq 60 \%$ in comparison with pure montmorillonite as a reference; this outcome might be due to the effect of the activated carbon additive and/or to the increase in the internal porosity of the composite material (see Tables 2 and 3).

From these data, a contact time of 120 min was selected for the isotherm experiments.

\subsection{Sorption isotherms and $p H$ effect}

\subsubsection{Montmorillonite}

The data for sorption onto pure montmorillonite can be described with the Langmuir isotherm model (Table 4). As expected from the $\mathrm{p} K_{\mathrm{a}}$ values of either phenol or $4 \mathrm{NP}$, the maximum sorption capacity decreases as $\mathrm{pH}$ increases.

\subsubsection{Activated carbon}

Similarly, the data (Table 4) show that the maximum sorption capacity for both compounds decreases as $\mathrm{pH}$ increases; moreover, as exemplified in other studies [3, 37, 38], these values are higher for 4NP than for phenol, in inverse correlation with their aqueous solubility (Table 1).

\subsection{3. $M A C C$}


The results of sorption isotherms for phenol and 4NP can also be represented by the Langmuir model (Fig. 2 for $X_{1}=80 \%$; Table 5). Regardless of the MACC sorbent matrix composition, the low sorbate concentration proves to be efficient, and the maximum sorption capacity is higher than for the corresponding pure materials (Table 4). While the pore volumes remain relatively similar, the enhancement in sorptive behavior can be correlated with the solid surface area increase relative to pure montmorillonite (compare Tables 2 and 3); this property is probably due to the presence of $X_{2}=7 \%$ of activated carbon, as previously found for 1,10-phenanthroline [28].

\subsection{4. $p H$ effect}

It is well known that solution $\mathrm{pH}$ influences the sorption of phenolic compounds onto solid sorbents: phenols are ionizable, and the degree of sorption of the phenolate anions onto the geomaterial surface is primarily influenced by the surface charge on the sorbent, which in turn is related to its $\mathrm{pH}_{\mathrm{zpc}}$, i.e. the $\mathrm{pH}$ of zero point charge (Tables 2 and 3). For this reason, our experiments were performed using solutions at various initial $\mathrm{pH}$ values representative of real wastewater (i.e. $\mathrm{pH}=3,5$ or 8 ).

Although the MACC matrices were always positively charged $\left(\mathrm{pH}<\mathrm{pH}_{\mathrm{zpc}}\right)$, phenol remains present as a molecular species though 4NP speciation strongly varies: $100 \%$ as a neutral molecule at $\mathrm{pH} 3,99.3 \%$ at $\mathrm{pH}$, and only $12.4 \%$ at $\mathrm{pH} 8$. These findings easily explain the $\mathrm{pH}$ influence on the sorption of 4NP. In comparison, pure montmorillonite with $\mathrm{pH}_{\mathrm{zpc}}=8.3$ is nearly uncharged at $\mathrm{pH} 8$, which is why its sorptive capacity slightly decreases.

\subsection{Effect of montmorillonite weight fraction $X_{1}(\%)$ on sorption isotherms}

In Figure 3, the two adsorption isotherms of phenol and 4NP are compared at $\mathrm{pH}$ 3 on MACC sorbents with different weight fractions $\left(X_{1}\right)$ of montmorillonite. For the same equilibrium concentration of phenolic compounds in solution, the sorbed amount 
increases with $X_{1}$ as does the maximum sorbing capacity $q_{\max }$. The initial slope of the Langmuir isotherm curves can be described as a distribution coefficient $K_{\mathrm{d}}=q_{\mathrm{e}} / C_{\mathrm{e}}$ which also increases with $X_{1}$ (Table 6).

These results corroborate the assumption of a partitioning of either phenol or 4NP between the sorbate solution and the MACC solid sorbent. It may be worthwhile to speculate on possible mechanistic and/or thermodynamic reasons for any potential correlation between $K_{\mathrm{d}}$ and $X_{1}$ (Table 6): while these values follow the same order as the $n$-octanol/water partition coefficient $\log P_{\text {ow }}$ for the sorbates (Table 1), we can make the assumption that the thermodynamics (i.e. enthalpic and entropic contributions) of both partitioning processes are analogous.

\subsection{Comparison of phenol and 4NP sorption on MACC with other data from the}

\section{literature}

In recent years, a number of studies have focused on solid supports that are able to sorb phenol and chloro- and nitro-phenols, as reviewed by Lin and Juang [39] and then Park et al. [21]. Although a direct comparison of our MACC matrices with other sorbent materials is difficult, owing to the various experimental conditions applied, we can still claim that in general the MACC sorption capacity for phenol and 4NP is of the same order of magnitude as the values reported in the literature with other sorbents.

Aksu and Yener [40] investigated the biosorption of certain phenolic compounds from aqueous solutions on dried activated sludge: the maximum adsorption capacity was found to be $0.9 \mathrm{mmol} / \mathrm{g}$ for phenol. Using a series of diversely functionalized chitosan, Li et al. [41] obtained with cyclodextrin a specific increase in sorption capacity for 4-chloro phenol.

Furuya et al. [42] used chloro- and nitro-phenols as sorbates and granular activated carbon as the sorbent: they achieved an adsorption capacity of up to $4 \mathrm{mmol} / \mathrm{g}$. 
For 4NP on a ground commercial activated carbon, Nouri and Haghseresht [43] obtained a maximum capacity of $1.6 \mathrm{mmol} / \mathrm{g}$ at $\mathrm{pH} 2$ but only $0.48 \mathrm{mmol} / \mathrm{g}$ at $\mathrm{pH} 12$, due to solute ionization. On activated carbon fibers, the maximum capacity was measured at $1.09 \mathrm{mmol} / \mathrm{g}$ for phenol and $2.26 \mathrm{mmol} / \mathrm{g}$ for $4 \mathrm{NP}$ [44].

Fly ash sorbents were also tested for phenol sorption, yet with very low sorption capacities, e.g.: $7.1 \mu \mathrm{mol} / \mathrm{g}$ phenol and $8.3 \mu \mathrm{mol} / \mathrm{g} 4 \mathrm{NP}\left(\mathrm{pH} 4,30^{\circ} \mathrm{C}\right.$ ) on a bagasse fly ash [45], or $2.8 \mu \mathrm{mol} / \mathrm{g}$ phenol and $1.0 \mu \mathrm{mol} / \mathrm{g} 4 \mathrm{NP}\left(\mathrm{pH} 3,34{ }^{\circ} \mathrm{C}\right.$ ) on a coal fly ash [46].

Shu et al. [47] used aluminosilicate-based microporous materials (surfactantmodified Zr-pillared clays and zeolites) for substituted phenol sorption: they reported a sorption capacity of up to $0.75 \mathrm{mmol} / \mathrm{g}$ for phenol and $0.63 \mathrm{mmol} / \mathrm{g}$ for $4 \mathrm{NP}$ (on a high $\mathrm{Si} / \mathrm{Al}$ ratio zeolite at $\mathrm{pH} 7$ ). On a $\mathrm{Mg} / \mathrm{Al}$-mixed oxide derived from the corresponding layered double hydroxide, Chen et al. [15] obtained a sorption capacity of $0.50 \mathrm{mmol} / \mathrm{g}$ for phenol and as high as $2.64 \mathrm{mmol} / \mathrm{g}$ for $4 \mathrm{NP}$, although the final $\mathrm{pH}$ was $9-10$ regardless of its initial value for the sorbate solution. Nonetheless, the maximum sorption capacity for 4NP onto a series of organopalygorskites was in the range 0.19$0.30 \mathrm{mmol} / \mathrm{g}[48]$.

In a series of papers, Park et al. [22, 24, 25] prepared organo-montmorillonites with various cationic surfactants; the sorption capacities for 4-Cl and 4- $\mathrm{NO}_{2}$ phenol depend on the nature of the surfactant and its loading ( 1 or 2 times that of clay CEC), e.g. 0.16 to $0.33 \mathrm{mmol} / \mathrm{g}$ for $4 \mathrm{NP}$ at $23{ }^{\circ} \mathrm{C}$ [24] in the case of HDTMA (hexadecyltrimethylammonium bromide). Koyuncu et al. [20] compared the sorption capacities for 4NP onto a bentonite intercalated with either a cationic surfactant (HDTMA) or the non-ionic PEG (polyethyleneglycol butyl ether): 0.77 and $1.75 \mathrm{mmol} / \mathrm{g}$ at $30^{\circ} \mathrm{C}$, respectively. 
Recently, Liu et al. [38] reported data on the use of Metal-Organic Frameworks (MOF): they recorded the high selectivity of an $\mathrm{NH}_{2}$-functionalized Al-based MOF, thus allowing for an efficient separation of 4NP from phenol in their mixtures.

From this short review, we can estimate that our composite MACC geomaterials roughly behave as other similar sorbents described in the recent literature. Although their sorption capacity is in the low range from these data, we consider that our MACC sorbents have the advantage to add the mechanical stability from the cement component with the complementary sorptive properties of both the hydrophilic montmorillonite clay and the lipophilic activated carbon.

\section{Conclusion}

The constituents of MACC geomaterials were chosen in order to associate mechanical solidity (contributed by the cement and partially by the clay) with complementary sorption properties (contributed by both the activated carbon and clay mineral). Due to this solidification procedure, these sorbents may be used not only in batch processes but also in column systems, as previously described [27]. They can offer enhanced sorption capacity for phenolic compounds relative to pure montmorillonite, a phenomenon which primarily depends on the microporous structure and not just the surface area.

The removal of phenol and 4NP from aqueous solutions through sorption on MACC was found to be feasible at $\mathrm{pH}$ values of around 3, yet decreased significantly as $\mathrm{pH}$ increased: this finding is due both to a simultaneous change in surface charges and to partial solute ionization. The Langmuir sorption model adequately represented the experimental data and indicated that MACC sorbents showed a higher sorption capacity for $4 \mathrm{NP}\left(\approx 0.28 \mathrm{mmol} / \mathrm{g}\right.$ for $\left.X_{1}=80 \%\right)$ than for phenol $\left(\approx 0.25 \mathrm{mmol} / \mathrm{g}\right.$ for $\left.X_{1}=80 \%\right)$. 
On the basis of this order of sorption capacity, the main characteristics of phenol and 4NP that play an important role in sorption mechanisms are: hydrophobicity, water solubility, molecular volume, and acidity $\left(\mathrm{p} K_{\mathrm{a}}\right)$.

\section{Acknowledgments}

$\mathrm{MH}$ and OB would like to thank the Franco-Algerian Cooperation Program for their travel and residency grants. 


\section{References}

[1] O. Carmody, R. Frost, Y. Xi, S. Kokot, Adsorption of hydrocarbons on organo-claysImplications for oil spill remediation, J Colloid Interface Sci. 305 (2007)17-24.

[2] E.P. Ng, S. Mintova, Nanoporous materials with enhanced hydrophilicity and high water sorption capacity, Microporous Mesoporous Mater. 114 (2008) 1-26.

[3] A. Dąbrowski, P. Podkościelny, Z. Hubicki, M. Barczak, Adsorption of phenolic compounds by activated carbon - a critical review, Chemosphere 58 (2005) 1049-1070.

[4] A.C. de Oliveira Pimenta, J.E. Kilduff, Oxidative coupling and the irreversible adsorption of phenol by graphite, J.Colloid Interface Sci. 293 (2006) 278-289.

[5] Agency for Toxic Substances and Disease Registry (ATSDR). Toxicological Profile for nitrophenols. Atlanta, GA: U.S. Department of Health and Human Services, Public Health Service (1992). http://www.atsdr.cdc.gov/toxprofiles/tp50.pdf (accessed 10 June 2014).

[6] J.M. Chern, Y.W. Chien, Adsorption of nitrophenol onto activated carbon: isotherms and breakthrough curves, Water Res. 36 (2002) 647-655.

[7] R.E. Grim, Applied Clay Mineralogy, McGraw-Hill, New York, 1962.

[8] O. Bouras, M. Houari, H. Khalaf, Adsorption of some phenolic derivatives by surfactant treated Al-pillared Algerian bentonite, Toxicol. Environ. Chem. 70 (1999) 221-227.

[9] S.M. Koh, J.B. Dixon, Preparation and application of organominerals as sorbents of phenol, benzene and toluene, Appl. Clay Sci. 18 (2001) 111-122.

[10] C.L. Ake, M.C. Wiles, H.J. Huebner, T.J. McDonald, D. Cosgriff, M.B. Richardson, K.C. Donnelly, T.D. Phillips, Porous organoclay composite for the sorption of polycyclic aromatic hydrocarbons and pentachlorophenol from groundwater, Chemosphere 51 (2003) 835-844. 
[11] M.C. Wiles, H.J. Huebner, T.J. McDonald, K.C. Donnelly, T.D. Phillips, Matriximmobilized organoclay for the sorption of polycyclic aromatic hydrocarbons and pentachlorophenol from groundwater, Chemosphere 59 (2005) 1455-1464.

[12] F. Bergaya, A. Aouad, T. Mandalia, In: F. Bergaya, B.K.G. Theng, G. Lagaly (Eds.), Developments in Clay Science, Vol. 1 Handbook of Clay Science, Elsevier, Amsterdam, 2006, pp. 393-421.

[13] G. Lagaly, F. Bergaya, M. Vayer, In: F. Bergaya, B.K.G. Theng, G. Lagaly (Eds.), Developments in Clay Science, Vol. 1 Handbook of Clay Science, Elsevier, Amsterdam, 2006, pp. 979-1001.

[14] O. Bouras, J.C. Bollinger, M. Baudu, H. Khalaf, Adsorption of diuron and its degradation products from aqueous solutions by surfactant-modified pillared-clays, Appl. Clay Sci. 37 (2007) 240-250.

[15] S. Chen, Z.P. Xu, Q. Zhang, G.Q.M. Lu, Z.P. Hao, S. Liu, Studies on adsorption of phenol and 4-nitrophenol on $\mathrm{MgAl}$-mixed oxide derived from $\mathrm{MgAl}$-layered double hydroxide, Separ. Purif. Technol. 67 (2009) 194-200.

[16] O. Bouras, J.C. Bollinger, M. Baudu, Effect of humic acids on pentachlorophenol sorption to cetyltrimethylammonium-modified Fe- and Al-pillared-montmorillonites, Appl. Clay Sci. 50 (2010) 58-63.

[17] B. Cheknane, O. Bouras, M. Baudu, J.P. Basly, A. Cherguielaine, Granular inorganoorgano pillared clays (GIOCs): Preparation by wet granulation, characterization and application to the removal of a Basic dye (BY28) from aqueous solutions, Chem. Eng. J. 158 (2010) 528-534.

[18] M. Lezehari, J.P. Basly, M. Baudu, O. Bouras, Alginate encapsulated pillared clays: removal of a neutral/anionic biocide (pentachlorophenol) and a cationic dye (safranine) from aqueous solutions, Colloids Surf. A 366 (2010) 88-94. 
[19] F. Zermane, O. Bouras, M. Baudu, J.P. Basly, Cooperative co-adsorption of 4nitrophenol and Basic Yellow 28 dye onto an iron organo-inorgano pillared montmorillonite clay, J. Colloid Interface Sci. 350 (2010) 315-319.

[20] H. Koyuncu, N. Yildiz, U. Salgin, F. Köroğlu, A. Çalimli, Adsorption of o-, m- and p-nitrophenols onto organically modified bentonites, J. Hazard. Mater. 185 (2011) 1332-1339.

[21] Y. Park, G.A. Ayoko, R.L. Frost, Application of organoclays for the adsorption of recalcitrant organic molecules from aqueous media, J. Colloid Interface Sci. 354 (2011) 292-305.

[22] Y. Park, G.A. Ayoko, R.L. Frost, Characterisation of organoclays and adsorption of p-nitrophenol: Environmental application, J. Colloid Interface Sci. 360 (2011) 440456.

[23] M. Lezehari, M. Baudu, O. Bouras, J.P. Basly, Fixed-bed column studies of pentachlorophenol removal by use of alginate-encapsulated pillared clay microbeads, J. Colloid Interface Sci. 379 (2012) 101-106.

[24] Y. Park, G.A. Ayoko, E. Horváth, R. Kurdi, J. Kristof, R.L. Frost, Structural characterisation and environmental application of organoclays for the removal of phenolic compounds, J. Colloid Interface Sci. 393 (2013) 319-334.

[25] Y. Park, G.A. Ayoko, R. Kurdi, E. Horváth, J. Kristof, R.L. Frost, Adsorption of phenolic compounds by organoclays: Implications for the removal of organic pollutants from aqueous media, J. Colloid Interface Sci. 406 (2013) 196-208.

[26] B. Hamdi, M. Houari, S. Ait Hamoudi, Z. Kessaïssia, Adsorption of some volatile organic compounds on geomaterials, Desalination 166 (2004) 449-455. 
[27] M. Houari, B. Hamdi, J. Brendle, O. Bouras, J.C. Bollinger, M. Baudu, Dynamic sorption of ionizable organic compounds (IOCs) and xylene from water using geomaterial-modified montmorillonite, J. Hazard. Mater. 147 (2007) 738-745.

[28] E.A. Ferreiro, S.G. de Bussetti, Apparent and partial specific adsorption of 1,10phenanthroline on mixtures of Ca-montmorillonite, activated carbon and silica gel, J. Colloid Interface Sci. 292 (2005) 54-62.

[29] C. Achard, M. Jaoui, M. Schwing, M. Rogalski, Aqueous solubilities of phenol derivatives by conductivity measurements, J. Chem. Eng. Data 41 (1996) 504-507.

[30] M.H. Abraham, C.M. Du, J.A. Platts, Lipophilicity of the nitrophenols, J. Org. Chem. 65 (2000) 7114-7118.

[31] U.S. Environmental Protection Agency. SW-846 Method 9081 - Cation Exchange Capacity of Soils (Sodium Acetate) (1986). http://www.epa.gov/wastes/hazard/testmethods/sw846/pdfs/9081.pdf (accessed 10 June 2014).

[32] V. Pallier, G. Feuillade-Cathalifaud, B. Serpaud, J.C. Bollinger, Effect of organic matter on arsenic removal during coagulation/flocculation treatment, J. Colloid Interface Sci. 342 (2010) 26-32.

[33] M. Davranche, S. Lacour, F. Bordas, J.C. Bollinger, An easy determination of the surface chemical properties of simple and natural solids, J. Chem. Educ. 80 (2003) 7678.

[34] E. Paineau, I. Bihannic, C. Baravian, A.M. Philippe, P. Davidson, P. Levitz, S.S. Funari, C. Rochas, L.J. Michot, Aqueous suspensions of natural swelling clay minerals. 1. Structure and electrostatic interactions, Langmuir 27 (2011) 5562-5573.

[35] E.M. Pecini, M.J. Avena, Measuring the isoelectric point of the edges of clay mineral particles: The case of montmorillonite, Langmuir 29 (2013) 14926-14934. 
[36] Z. Adamis, R.B. Williams, Bentonite, Kaolin and Selected Clay Minerals

(Environmental Health Criteria 231), WHO, Geneva, 2005.

[37] A. Kumar, S. Kumar, S. Kumar, D.V. Gupta, Adsorption of phenol and 4-nitrophenol on granular activated carbon in basal salt medium: Equilibrium and kinetics, J. Hazard. Mater. 147 (2007) 155-166.

[38] B.J. Liu, F. Yang, Y.X. Zou, Y. Peng, Adsorption of phenol and p-nitrophenol from aqueous solutions on Metal-Organic Frameworks: Effect of hydrogen bonding, J. Chem. Eng. Data 59 (2014) 1476-1482.

[39] S.H. Lin, R.S. Juang, Adsorption of phenol and its derivatives from water using synthetic resins and low-cost natural adsorbents: a review, J. Environ. Manag. 90 (2009) 1336-1349.

[40] Z. Aksu, J. Yener, Investigation of the biosorption of phenol and monochlorinated phenols on the dried activated sludge, Process Biochem. 33 (1998) 649-655.

[41] J.M. Li, X.G. Meng, C.W. Hu, J. Du, Adsorption of phenol, p-chlorophenol and pnitrophenol onto functional chitosan, Biores. Technol. 100 (2009) 1168-1173.

[42] E.G. Furuya, H.T. Chang, Y. Miura, K. E. Noll, A fundamental analysis of the isotherm for the adsorption of phenolic compounds on activated carbon, Separ. Purif. Technol. 11 (1997) 69-78.

[43] S. Nouri, F. Haghseresht, Adsorption of p-nitrophenol in untreated and treated activated carbon, Adsorption 10 (2004) 79-86.

[44] Q.S. Liu, T. Zheng, P. Wang, J.P. Jiang, N. Li, Adsorption isotherm, kinetic and mechanism studies of some substituted phenols on activated carbon fibers, Chem. Eng. J. 157 (2010) 348-356. 
[45] V.K. Gupta, S. Sharma, I.S. Yadav, D. Mohan, Utilization of bagasse fly ash generated in the sugar industry for the removal and recovery of phenol and pnitrophenol from wastewater, J. Chem. Technol. Biotechnol. 71 (1998) 180-186.

[46] J.H. Potgieter, S.O. Bada, S.S. Potgieter-Vermaak, Adsorptive removal of various phenols from water by South African coal fly ash, Water SA 35 (2009) 89-96.

[47] H.T. Shu, D. Li, A.A. Scala, Y.H. Ma, Adsorption of small organic pollutants from aqueous streams by aluminosilicate-based microporous materials, Separ. Purif. Technol. 11 (1997) 27-36.

[48] B. Sarkar, Y. Xi, M. Megharaj, G.S.R. Krishnamurti, R. Naidu, Synthesis and characterisation of novel organopalygorskites for removal of p-nitrophenol from aqueous solution: Isothermal studies, J. Colloid Interface Sci. 350 (2010) 295-304. 


\section{List of Table and Figure Captions.-}

Table 1. Main physicochemical properties of the sorbates.

Table 2. Main physicochemical properties of the starting materials.

Table 3. Selected MACC geomaterial properties.

Table 4. Parameters of the Langmuir sorption model for phenol compounds onto pure montmorillonite or activated carbon.

Table 5. Effect of $\mathrm{pH}$ on the Langmuir sorption model parameters for phenol compounds onto MACC sorbents.

Table 6. Initial distribution coefficient $K_{\mathrm{d}}(\mathrm{L} / \mathrm{g})$ for phenol and $4 \mathrm{NP}$ onto MACC sorbents $v s$. montmorillonite weight fraction $X_{1}(\%)$ at $\mathrm{pH} 3$.

Fig. 1. Effect of weight fraction $X_{1}$ of montmorillonite in MACC on phenol and 4nitrophenol sorption kinetics $\left(C_{0}=0.72 \mathrm{mmol} / \mathrm{L} ; \mathrm{pH}=3 ; \mathrm{T}=20^{\circ} \mathrm{C}\right)$. The composite geomaterials (MACC) were prepared by mixing $X_{1} \%(\mathrm{w} / \mathrm{w})$ montmorillonite, $X_{2}=$ $7 \%$ activated carbon and cement $\left(X_{3}\right)$.

Fig. 2. $\mathrm{pH}$ effect for the sorption isotherms onto $\mathrm{MACC}\left(X_{1}=80 \%\right)\left(C_{0}=0.72 \mathrm{mmol} / \mathrm{L}\right.$; $\left.\mathrm{T}=20^{\circ} \mathrm{C}\right)$. Symbols $=$ experimental results; lines $=$ Langmuir model. The composite geomaterials (MACC) were prepared by mixing $X_{1} \%(\mathrm{w} / \mathrm{w})$ montmorillonite, $X_{2}=$ $7 \%$ activated carbon and cement $\left(X_{3}\right)$.

Fig. 3. Adsorption isotherms of phenol and $4 \mathrm{NP}$ by MACC at different weight fraction $X_{1}\left(C_{0}=0.72 \mathrm{mmol} / \mathrm{L} ; \mathrm{pH}=3 ; \mathrm{T}=20^{\circ} \mathrm{C}\right)$. Symbols $=$ experimental results; lines $=$ Langmuir model. The composite geomaterials (MACC) were prepared by mixing $X_{1}$ $\%(\mathrm{w} / \mathrm{w})$ montmorillonite, $X_{2}=7 \%$ activated carbon and cement $\left(X_{3}\right)$. 


\section{Table 1}

Main physicochemical properties of the sorbates.

\begin{tabular}{lll}
\hline Compound & Phenol & 4-Nitrophenol \\
\hline Molar mass $(\mathrm{g} / \mathrm{mol})$ & 94.11 & 139.11 \\
${\text { Solubility in water }(\mathrm{g} / \mathrm{L})^{\text {a }}}$ & 84.0 & 15.6 \\
$\log P_{\text {ow }}{ }^{\mathrm{a}}$ & 1.50 & 1.91 \\
$\mathrm{p} K_{\mathrm{a}}{ }^{\mathrm{c}}$ & 9.92 & 7.15 \\
$V_{\operatorname{mol}}(\mathrm{mL} / \mathrm{mol}){ }^{\text {d }}$ & 77.5 & 94.9 \\
$\lambda_{\max }(\mathrm{nm})^{\mathrm{e}}$ & 269 & 285 \\
\hline
\end{tabular}

${ }^{a}$ at $25^{\circ} \mathrm{C}$; from Achard et al. [29]

${ }^{\mathrm{b}}$ Lipophilicity in octanol/water; from Abraham et al. [30]

${ }^{c}$ Acidity constant; cited in Achard et al. [29]

${ }^{d}$ McGowan's characteristic molar volume; from Abraham et al. [30]

${ }^{\mathrm{e}}$ Characteristic wavelength for detection; this study 


\section{Table 2}

Main physicochemical properties of the starting materials.

\begin{tabular}{llll}
\hline Property & Montmorillonite & Activated Carbon & Cement \\
\hline Particle size $(\mu \mathrm{m})$ & $<2$ & $<20$ & $200-250$ \\
Humidity $(\%)$ & 9 & 7.8 & 2.5 \\
$S_{\mathrm{BET}}\left(\mathrm{m}^{2} / \mathrm{g}\right)^{\mathrm{a}}$ & 90 & 950 & 12 \\
$V_{\mathrm{p}}\left(\mathrm{cm}^{3} / \mathrm{g}\right)^{\mathrm{b}}$ & 0.11 & 0.37 & 0.09 \\
$\mathrm{CEC}(\mathrm{eq} / \mathrm{g})^{\mathrm{c}}$ & $86.5 \times 10^{-5}$ & -- & $92.8 \times 10^{-5}$ \\
$\zeta(\mathrm{mV})^{\mathrm{d}}$ & -55 & -21 & -10 \\
$\mathrm{pH}_{\text {zpc }}$ & ${ }^{\mathrm{c}}$ & 7.3 & 9.6 \\
\hline
\end{tabular}

${ }^{a}$ Specific surface area, determined by the BET method

${ }^{\mathrm{b}}$ Pore volume, from the BET measurements

${ }^{\mathrm{c}}$ Cationic exchange capacity

${ }^{\mathrm{d}}$ Zeta-potential $( \pm 6 \mathrm{mV})$

${ }^{\mathrm{e}} \mathrm{pH}$ of zero point charge $( \pm 0.1)$ 
Table 3

Selected MACC geomaterial properties.

\begin{tabular}{llll}
\hline$X_{1}(\% \mathrm{w} / \mathrm{w})^{\mathrm{a}}$ & 60 & 70 & 80 \\
\hline $\mathrm{S}_{\mathrm{BET}}\left(\mathrm{m}^{2} / \mathrm{g}\right)^{\mathrm{b}}$ & 80 & 110 & 140 \\
$V_{\mathrm{p}}\left(\mathrm{cm}^{3} / \mathrm{g}\right)^{\mathrm{c}}$ & 0.12 & 0.13 & 0.15 \\
$\mathrm{CEC}(\mathrm{eq} / \mathrm{g})^{\mathrm{d}}$ & $54.6 \times 10^{-5}$ & $57.4 \times 10^{-5}$ & $63.5 \times 10^{-5}$ \\
$\zeta(\mathrm{mV})^{\mathrm{e}}$ & -142 & -132 & -95 \\
$\mathrm{pH}_{\mathrm{zpc}}$ & 11.0 & 11.0 & 9.8 \\
\hline
\end{tabular}

a The composite geomaterials (MACC) were prepared by mixing $X_{1} \%(\mathrm{w} / \mathrm{w})$ montmorillonite, $X_{2}=7 \%$ activated carbon and cement $\left(X_{3}\right)$

${ }^{\mathrm{b}}$ Specific surface area, determined by the BET method

${ }^{\mathrm{c}}$ Pore volume, from the BET measurements

${ }^{\mathrm{d}}$ Cationic exchange capacity

e Zeta-potential $( \pm 6 \mathrm{mV})$

${ }^{\mathrm{f}} \mathrm{pH}$ of zero point charge $( \pm 0.1)$ 
Table 4

Parameters of the Langmuir sorption model for phenolic compounds onto pure montmorillonite or activated carbon.

\begin{tabular}{llcccccc}
\hline Sorbate & \multicolumn{3}{c}{ Montmorillonite } & \multicolumn{3}{c}{ Activated Carbon } \\
\hline \multirow{4}{*}{ Phenol } & $\mathrm{pH}$ & $\begin{array}{c}q_{\max } \\
(\mathrm{mmol} / \mathrm{g})\end{array}$ & $\begin{array}{c}K_{\mathrm{L}} \\
(\mathrm{L} / \mathrm{mmol})\end{array}$ & $R^{2}$ & $\begin{array}{c}q_{\max } \\
(\mathrm{mmol} / \mathrm{g})\end{array}$ & $\begin{array}{c}K_{\mathrm{L}} \\
(\mathrm{L} / \mathrm{mmol})\end{array}$ & $R^{2}$ \\
& 3 & 0.13 & 1.35 & 0.99 & 0.07 & 2.13 & 0.99 \\
& 5 & 0.11 & 2.36 & 0.99 & 0.06 & 2.97 & 0.98 \\
$4 \mathrm{NP}$ & 8 & 0.05 & 4.10 & 0.99 & 0.04 & 6.55 & 0.98 \\
& 3 & 0.11 & 3.09 & 0.99 & 0.21 & 2.10 & 0.99 \\
& 5 & 0.07 & 4.14 & 0.98 & 0.15 & 4.67 & 0.98 \\
& 8 & 0.05 & 7.06 & 0.99 & 0.17 & 1.90 & 0.97 \\
\hline
\end{tabular}




\section{Table 5}

Effect of $\mathrm{pH}$ on the Langmuir sorption model parameters for phenolic compounds onto MACC sorbents. ${ }^{\text {a }}$

\begin{tabular}{|c|c|c|c|c|c|c|c|c|c|c|}
\hline Sorbate & $\mathrm{pH}$ & $X_{1}=60 \%$ & & & $X_{1}=70 \%$ & & & $X_{1}=80 \%$ & & \\
\hline & & $q_{\max }$ & $K_{\mathrm{L}}$ & $R^{2}$ & $q_{\max }$ & $K_{\mathrm{L}}$ & $\overline{R^{2}}$ & $q_{\max }$ & $K_{\mathrm{L}}$ & $R^{2}$ \\
\hline & & $(\mathrm{mmol} / \mathrm{g})$ & (L/mmol) & & $(\mathrm{mmol} / \mathrm{g})$ & $(\mathrm{L} / \mathrm{mmol})$ & & $(\mathrm{mmol} / \mathrm{g})$ & $(\mathrm{L} / \mathrm{mmol})$ & \\
\hline \multirow[t]{3}{*}{ Phenol } & 3 & 0.21 & 1.13 & 0.98 & 0.25 & 1.15 & 0.97 & 0.25 & 3.07 & 0.99 \\
\hline & 5 & 0.10 & 2.20 & 0.98 & 0.20 & 2.22 & 0.96 & 0.17 & 2.81 & 0.99 \\
\hline & 8 & 0.08 & 2.30 & 0.95 & 0.07 & 2.35 & 0.97 & 0.13 & 1.76 & 0.99 \\
\hline \multirow[t]{3}{*}{$4 \mathrm{NP}$} & 3 & 0.15 & 6.79 & 0.98 & 0.18 & 6.21 & 0.98 & 0.28 & 10.3 & 0.99 \\
\hline & 5 & 0.06 & 6.50 & 0.98 & 0.08 & 7.20 & 0.98 & 0.19 & 12.7 & 0.94 \\
\hline & 8 & 0.10 & 7.20 & 0.99 & 0.14 & 7.80 & 0.97 & 0.22 & 7.48 & 0.98 \\
\hline
\end{tabular}

a The composite geomaterials (MACC) were prepared by mixing $X_{1} \%(\mathrm{w} / \mathrm{w})$ montmorillonite, $X_{2}=7 \%$ activated carbon and cement $\left(X_{3}\right)$ 


\section{Table 6}

Initial distribution coefficient $K_{\mathrm{d}}(\mathrm{L} / \mathrm{g})$ for phenol and 4NP onto MACC sorbents $v s$. montmorillonite weight fraction $X_{1}(\%)$ at $\mathrm{pH} 3$. $^{\mathrm{a}}$

\begin{tabular}{lllll}
\hline$X_{1}(\%)$ & Phenol & & $4 \mathrm{NP}$ & \\
\hline & $K_{\mathrm{d}}(\mathrm{L} / \mathrm{g})$ & $R^{2}$ & $K_{\mathrm{d}}(\mathrm{L} / \mathrm{g})$ & $R^{2}$ \\
60 & 0.17 & 0.98 & 0.37 & 0.98 \\
70 & 0.22 & 0.97 & 0.45 & 0.98 \\
80 & 0.38 & 0.99 & 0.67 & 0.99 \\
\hline
\end{tabular}

a The composite geomaterials (MACC) were prepared by mixing $X_{1} \%(\mathrm{w} / \mathrm{w})$ montmorillonite, $X_{2}=7 \%$ activated carbon and cement $\left(X_{3}\right)$ 

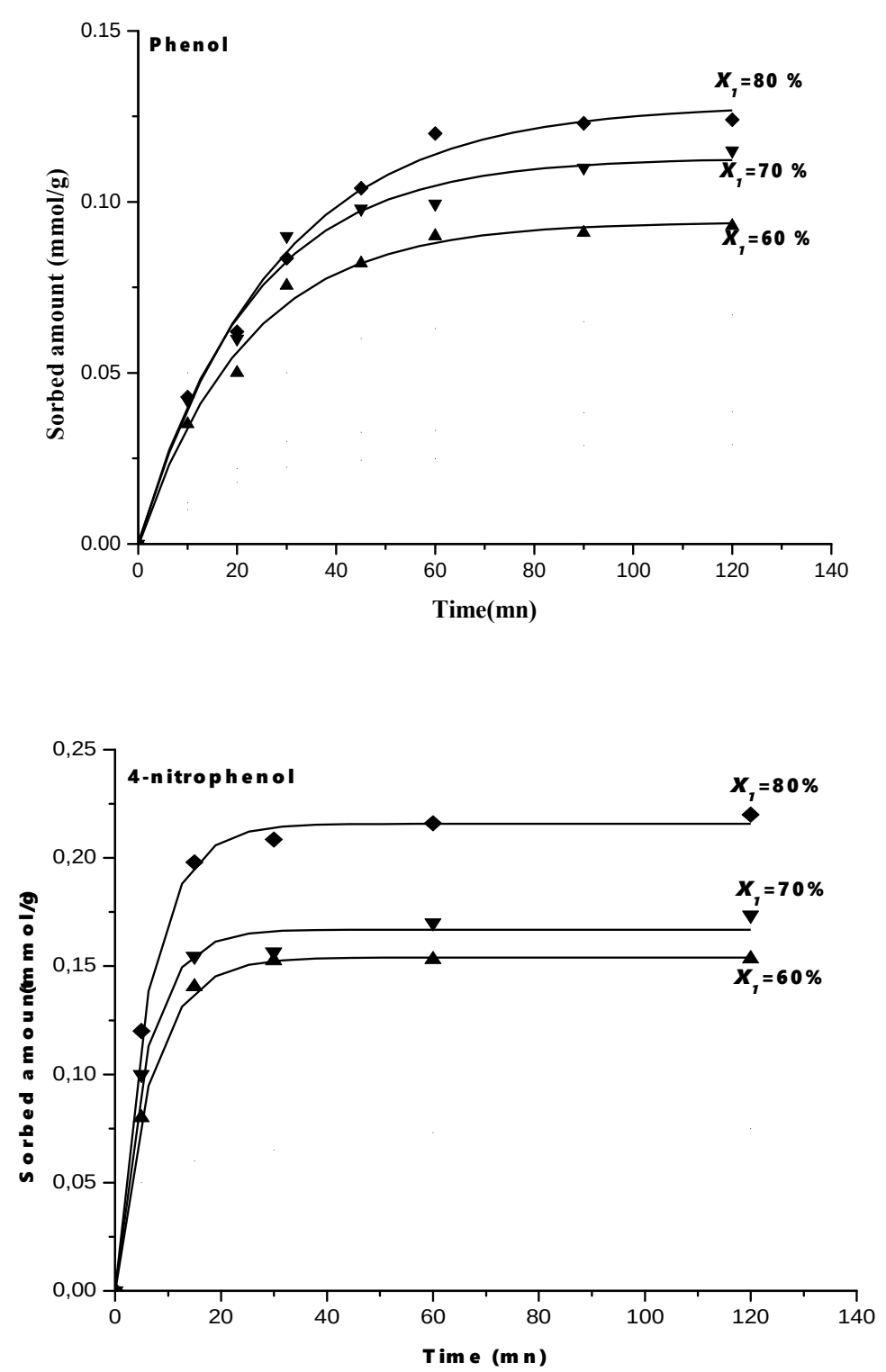

Fig. 1. Effect of weight fraction $X_{1}$ of montmorillonite in MACC on phenol and 4nitrophenol sorption kinetics $\left(\mathrm{C}_{0}=0.72 \mathrm{mmol} / \mathrm{L} ; \mathrm{pH}=3 ; \mathrm{T}=20^{\circ} \mathrm{C}\right)$. The composite geomaterials (MACC) were prepared by mixing $X_{1} \%(\mathrm{w} / \mathrm{w})$ montmorillonite, $X_{2}=7 \%$ activated carbon and cement $\left(X_{3}\right)$. 

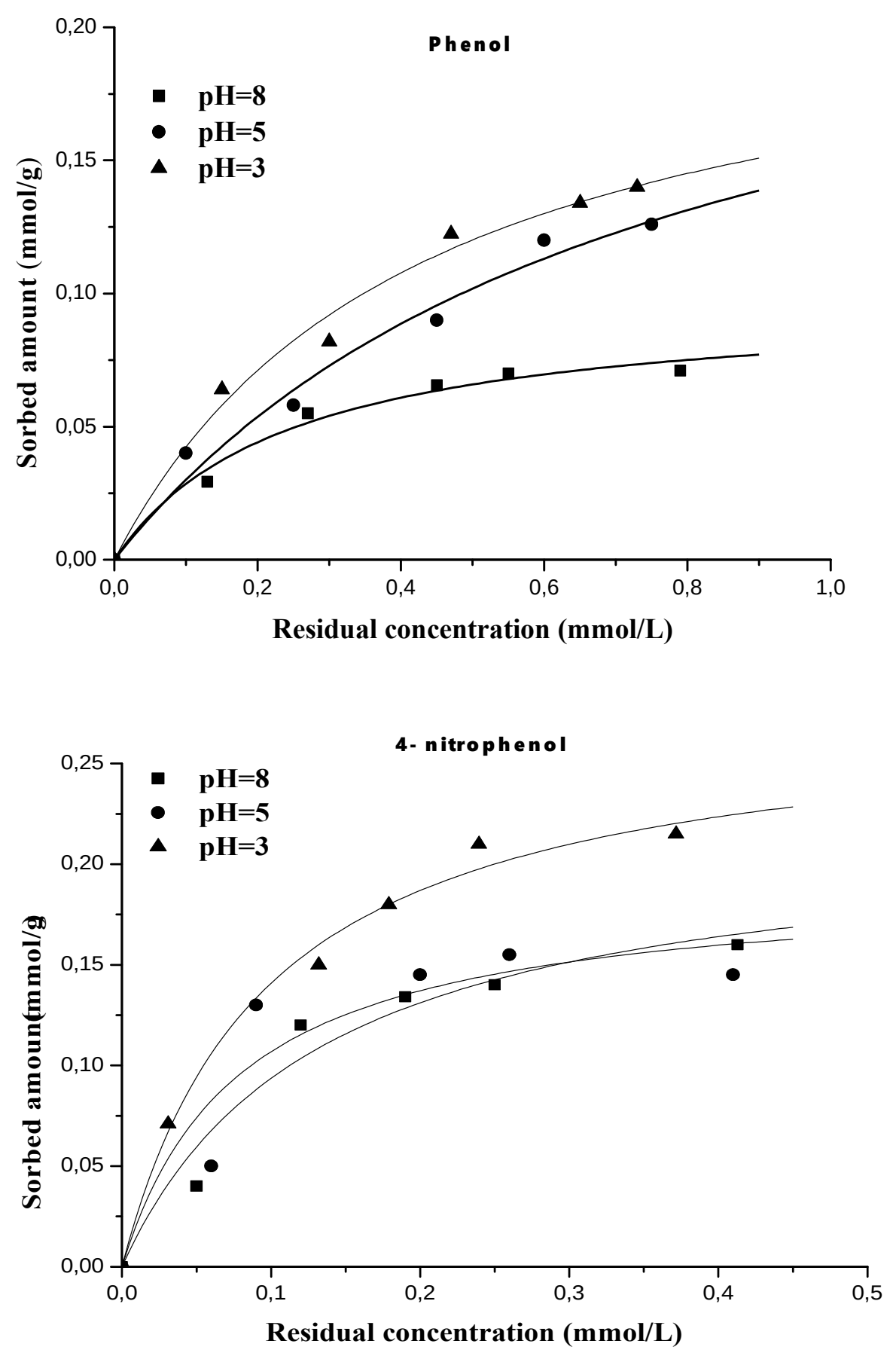

Fig. 2. $\mathrm{pH}$ effect for the sorption isotherms onto MACC $\left(X_{1}=80 \%\right)\left(\mathrm{C}_{0}=0.72 \mathrm{mmol} / \mathrm{L} ; \mathrm{T}=\right.$ $\left.20{ }^{\circ} \mathrm{C}\right)$. Symbols $=$ experimental results; lines $=$ Langmuir model. The composite geomaterials (MACC) were prepared by mixing $X_{1} \%(\mathrm{w} / \mathrm{w})$ montmorillonite, $X_{2}=7 \%$ activated carbon and cement $\left(X_{3}\right)$. 

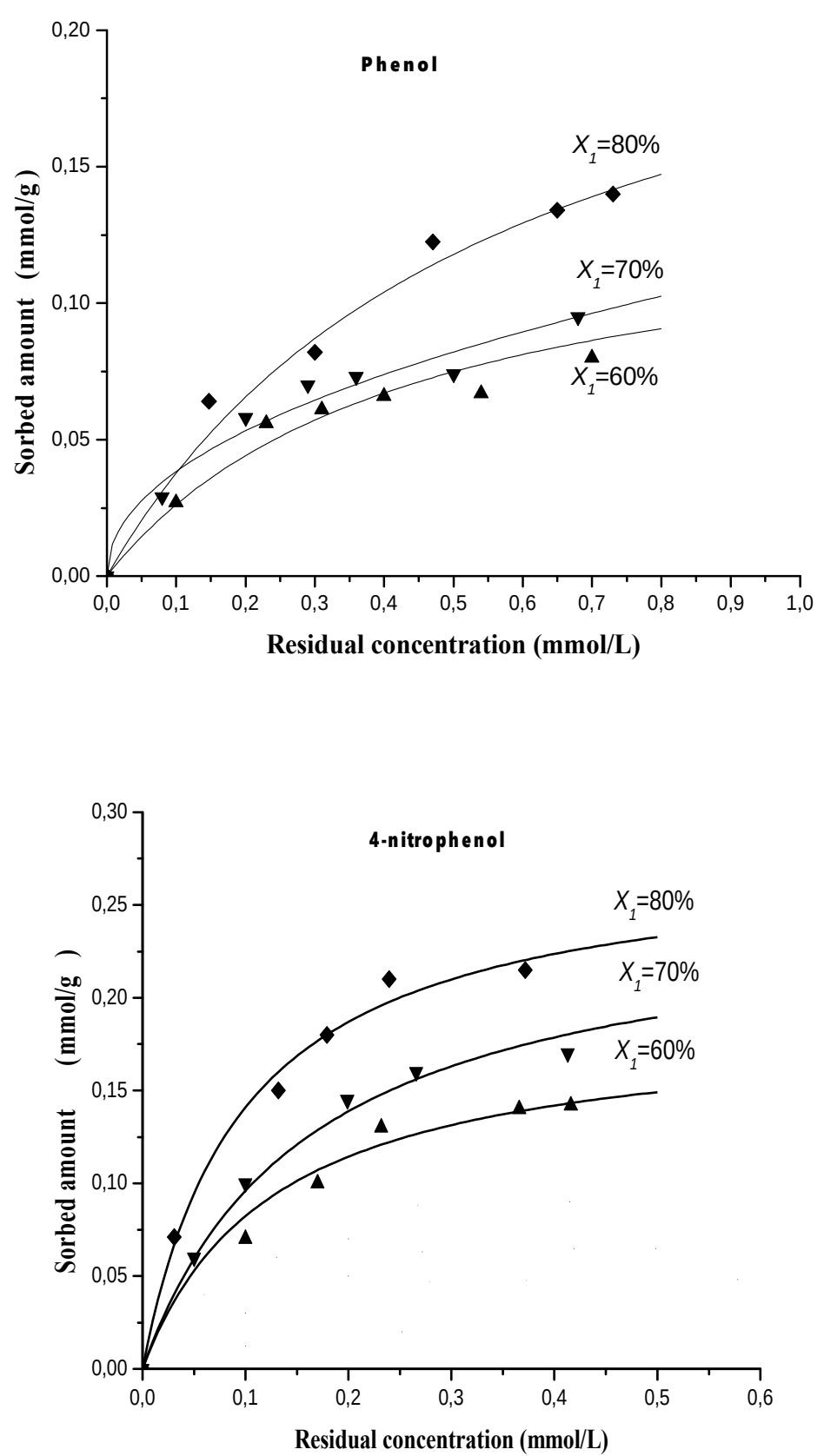

Fig. 3. Adsorption isotherms of phenol and $4 \mathrm{NP}$ by MACC at different weight fraction $X_{1}\left(\mathrm{C}_{0}=\right.$ $\left.0.72 \mathrm{mmol} / \mathrm{L} ; \mathrm{pH}=3 ; \mathrm{T}=20^{\circ} \mathrm{C}\right)$. Symbols $=$ experimental results; lines $=$ Langmuir model. The composite geomaterials (MACC) were prepared by mixing $X_{1} \%(\mathrm{w} / \mathrm{w})$ montmorillonite, $X_{2}$ $=7 \%$ activated carbon and cement $\left(X_{3}\right)$. 